\title{
Depletion of SNAP-23 and Syntaxin 4 alters lipid droplet homeostasis during Chlamydia infection
}

\author{
Tiago Monteiro-Brás ${ }^{1,2,3}$, Jordan Wesolowski ${ }^{1, *}$ and Fabienne Paumet ${ }^{1, *}$ \\ ${ }^{1}$ Department of Microbiology and Immunology, Thomas Jefferson University, Philadelphia, PA, USA 19107. \\ ${ }^{2}$ Life and Health Sciences Research Institute (ICVS), School of Medicine, University of Minho, 4710-057 Braga, Portugal. \\ ${ }^{3}$ ICVS/3B's, PT Government Associate Laboratory, 4710-057, Braga/Guimarães, Portugal. \\ * Corresponding Authors: \\ Fabienne Paumet, 233 South 10th Street, Bluemle Life Sciences building room 750, \\ Philadelphia, PA 19104; Phone: 215-503-8567; Fax: 215-923-6852; E-mail: Fabienne.Paumet@Jefferson.edu; \\ Jordan Wesolowski, 233 South 10th Street, Bluemle Life Sciences building room 750, \\ Philadelphia, PA 19104; Phone: 215-503-8566; Fax: 215-923-6852; E-mail: Jordan.Wesolowski@Jefferson.edu
}

\begin{abstract}
Chlamydia trachomatis is an obligate intracellular pathogen that replicates inside a parasitic vacuole called the inclusion. The nascent inclusion is derived from the host plasma membrane and serves as a platform from which Chlamydia controls interactions with the host microenvironment. To survive inside the host cell, Chlamydia scavenges for nutrients and lipids by recruiting and/or fusing with various cellular compartments. The mechanisms by which these events occur are poorly understood but require host proteins such as the SNARE proteins (SNAP (Soluble $\mathrm{N}$-ethylmaleimide-sensitive factor attachment protein) Receptor). Here, we show that SNAP-23 and Syntaxin 4, two plasma membrane SNAREs, are recruited to the inclusion and play an important role in Chlamydia development. Knocking down SNAP-23 and Syntaxin 4 by CRISPR-Cas9 reduces the amount of infectious progeny. We then demonstrate that the loss of both of these SNARE proteins results in the dysregulation of Chlamydia-induced lipid droplets, indicating that both SNAP23 and Syntaxin 4 play a critical role in lipid droplet homeostasis during Chlamydia infection. Ultimately, our data highlights the importance of lipid droplets and their regulation in Chlamydia development.
\end{abstract}

doi: $10.15698 / \mathrm{mic} 2020.02 .707$ Received originally: 03.09.2019; in revised form: 18.11.2019, Accepted 27.11.2019, Published 03.12.2019.

Keywords: lipid droplets, Chlamydia, SNARE, intracellular bacteria, inclusion.
Abbreviations:
$E B$ - elementary body,
$E R$ - endoplasmic reticulum,
FA - fatty acid,
hGH - human growth hormone,
KD- knock down,
LD-lipid droplet,
$\mathrm{MOI}$ - multiplicity of infection,
$O A$ - oleic acid,
pi-post infection,
$R T$-room temperature,
$S M$ - sphingomyelin,
SNAP - soluble N-ethylmaleimide-
sensitive factor attachment protein,
SNARE - SNAP receptor,
t-SNARE - target SNARE,
V-SNARE - vesicular SNARE,
$W T$ - wild type.

\section{INTRODUCTION}

Chlamydia trachomatis is the most common agent of bacterial sexually-transmitted infections with an estimated worldwide incidence of $\sim 130$ million cases per year $[1,2]$. C. trachomatis is also the leading cause of preventable infectious blindness, called trachoma [3-5]. The rise in C. trachomatis infections, despite the availability of antibiotics, is compounded by the asymptomatic nature of disease progression. Consequently, untreated infections result in long-term complications, including pelvic inflamma- tory disease, ectopic pregnancy, and infertility [6]. Antibiotic treatment can also induce persistence, prolonging interactions between Chlamydia and its host, thus increasing the risk of developing chronic diseases [7-9].

C. trachomatis is an obligate intracellular pathogen with a unique developmental cycle consisting of distinct extracellular and intracellular forms [10, 11]. Elementary bodies (EBs) are the extracellular form and exhibit low metabolic activity, while reticulate bodies (RBs) are the metabolically active, replicative, but non-infectious, intra- 
cellular form. EBs promote their uptake into host epithelial cells by inducing local actin polymerization at the plasma membrane [12]. Once internalized, $C$. trachomatis remains inside a membrane-bound vacuole, called the inclusion. The nascent inclusion is derived from the plasma membrane but it acquires additional intracellular sources of lipids to support its considerable growth and expansion during Chlamydia's life cycle. Ultimately, mature inclusions exceed the size of the host cell nucleus and occupy most of the cell's cytoplasm.

The intracellular survival of Chlamydia depends on its ability to control an array of interactions between the host and the inclusion, including contact with cellular organelles, which allow Chlamydia to scavenge for nutrients and lipids. Previous studies have demonstrated that Chlamydia acquires sphingomyelin and cholesterol by hijacking Golgi-derived vesicles that are destined for the plasma membrane [13-17]. In addition to the Golgi, the inclusion interacts with the endoplasmic reticulum (ER) [18-20], peroxisomes [21], and multivesicular bodies [22, 23]. C. trachomatis also utilizes host fatty acids (FA) to promote its growth. In eukaryotic cells, lipid droplets (LDs) are the primary site of FA storage and they have been shown to be involved in the intracellular development of Chlamydia [2426]. C. trachomatis increases the LD content of its host cell during infection, and LD-like structures have also been reported in the lumen of chlamydial inclusions [25], suggesting that LDs are an important facet of Chlamydia infection.

C. trachomatis acquires resources from the host using multiple strategies, including diffusion mechanisms through transmembrane transporters, direct transfer of lipids at contact sites, and vesicle fusion [16, 27-31], the latter being mediated by SNARE proteins. The assembly of a specific vesicular SNARE (v-SNARE) with its cognate target SNARE (t-SNARE) complex into a stable four-helix bundle provides the energy necessary to disrupt and merge lipid bilayers during membrane fusion [32-35]. Chlamydia has been shown to control lipid acquisition by co-opting certain SNARE-mediated pathways. For instance, the siRNAmediated depletion of Syntaxin 10 results in the retention of sphingomyelin in the inclusion while the depletion of VAMP-4 inhibits sphingomyelin trafficking to the inclusion [36-38]. In turn, by co-opting these pathways, Chlamydia enhances its survival inside the host cell $[15,16]$. While these studies have begun to shed light on the role that SNARE proteins play during infection, the extent to which Chlamydia hijacks SNARE-mediated membrane fusion is unknown.

During internalization, the nascent inclusion membrane is formed from the host cell plasma membrane. Thus, this early membrane composition likely gives the inclusion distinct functional properties that would dictate interactions between the inclusion and the host cell. A number of SNARE proteins, including SNAP-23, Syntaxin 3, and Syntaxin 4 , are located on the plasma membrane [39, 40]. Whether any of these SNAREs are retained on or excluded from the inclusion membrane is unknown.
In this study, we show that the SNAREs SNAP-23 and Syntaxin 4 are recruited to the chlamydial inclusion and that their depletion correlates with a decrease in infectious progeny, indicating that these plasma membrane SNAREs are important for $C$. trachomatis development. Interestingly, C. trachomatis infection does not affect constitutive secretion, which suggests that the function of both of these SNAREs is independent of their role in mediating membrane fusion at the plasma membrane. Instead, the loss of SNAP-23 and Syntaxin 4 results in a significant increase in Chlamydia-induced LDs, demonstrating that these SNAREs play an important role in controlling LD homeostasis during infection, which ultimately impacts Chlamydia development.

\section{RESULTS}

SNAP-23, Syntaxin 3, and Syntaxin 4 are recruited to the chlamydial inclusion

To determine whether the plasma membrane SNAREs SNAP-23, Syntaxin 3, and Syntaxin 4 play a role during Chlamydia infection, we first assessed their localization during infection. To do so, we infected HeLa cells with C. trachomatis $4 \mathrm{~h}$ prior to transfection with CDNA encoding either 3xFLAG-SNAP-23, 3xFLAG-Syntaxin 3 or 3x-FLAGSyntaxin 4. As a negative control, we transfected cells with a plasmid encoding soluble GFP. The cells were then fixed $24 \mathrm{~h}$ post infection (pi) and co-labeled with anti-FLAG antibody to determine the localization of each SNARE, as well as anti-IncA antibody to label the inclusion membrane. As shown in Figure 1, SNAP-23, Syntaxin 3, and Syntaxin 4, but not GFP, relocate to the inclusion where they are coincident with the inclusion membrane protein IncA (Fig. 1, zoom and line scans). The recruitment of these SNAREs was prevalent in cells expressing different levels of 3xFLAGSNAREs (Fig. S1). Although previous studies have not detected endogenous or epitope-tagged Syntaxin 4 at the inclusion $[38,41]$, this may be due to method and timing of fixation. In our study, cells were fixed at $24 \mathrm{~h}$ pi with paraformaldehyde compared to $18 \mathrm{~h}$ pi with methanol in [38, 41]. We have found that the method and timing of fixation greatly influences the detection of SNARE proteins during Chlamydia infection (data not shown).

SNAP-23 encodes two light chains that interact either with the heavy chain Syntaxin 3 or Syntaxin 4 to form two distinct t-SNARE complexes [42]. Since these SNAREs are recruited to the inclusion, we tested whether Chlamydia infection impacts Syntaxin 3/SNAP-23 and Syntaxin 4/SNAP-23 t-SNARE complex formation. To do so, cells were infected with wild type (WT) $C$. trachomatis or mock infected and transfected at $4 \mathrm{~h}$ pi with a plasmid encoding 3xFLAG-SNAP-23. At $24 \mathrm{~h}$ pi, the samples were subjected to co-immunoprecipitation with anti-FLAG antibody and complex formation was analyzed by Western blot. As shown in Figure S2, comparable amounts of Syntaxin 3 and Syntaxin 4 co-immunoprecipitated with SNAP-23 in noninfected and $C$. trachomatis-infected cells.

Together, these results demonstrate that $C$. trachomatis recruits SNAP-23, Syntaxin 3, and Syntaxin 4 to the 


\section{A 3xFLAG- SNAP-23}
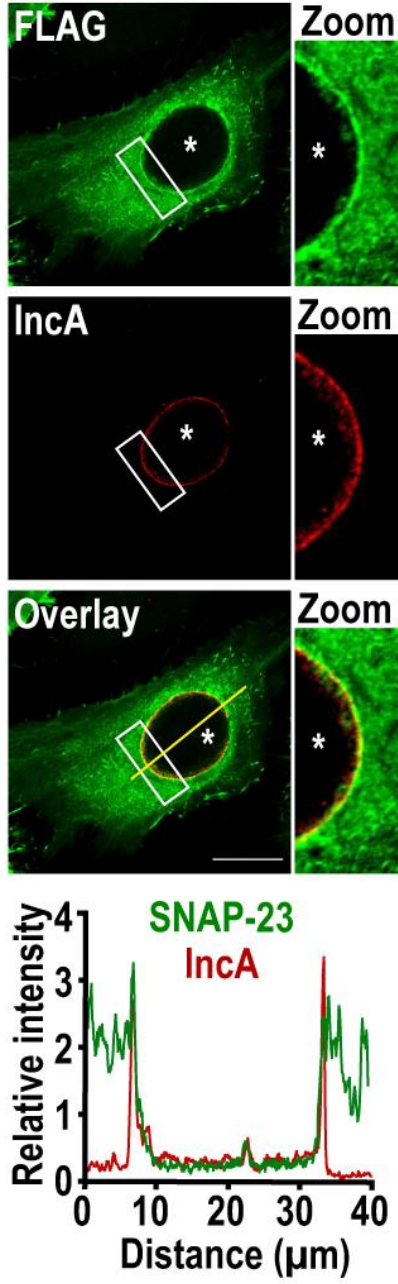

Zoom

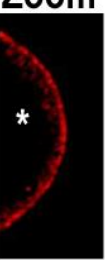

Zoom
B 3xFLAGSyntaxin 3
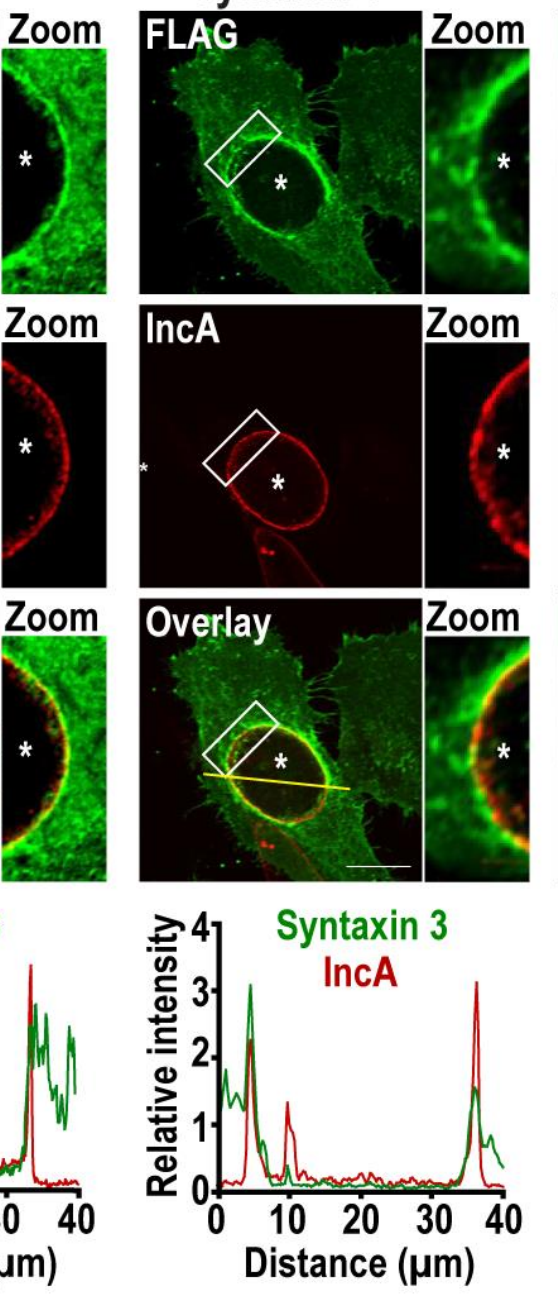

C 3xFLAGSyntaxin 4
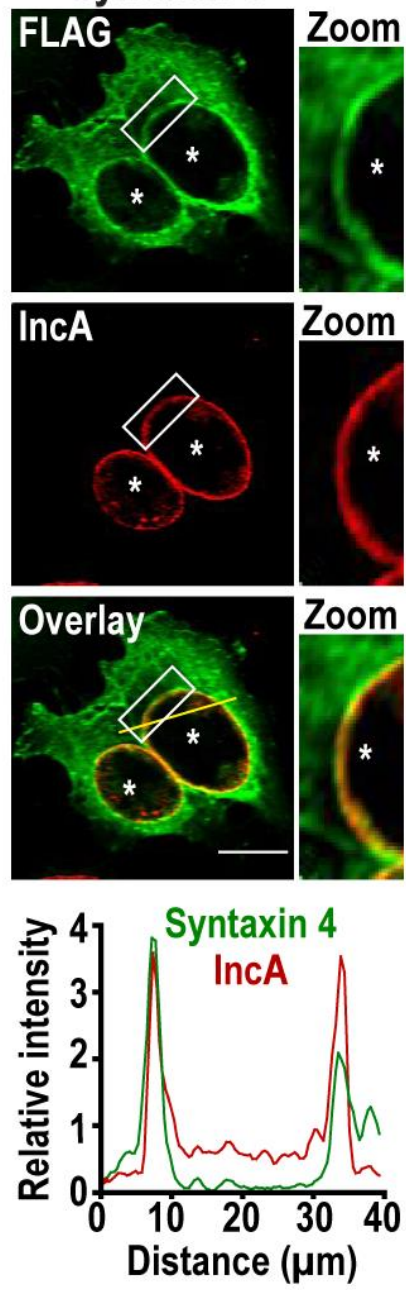

D Soluble

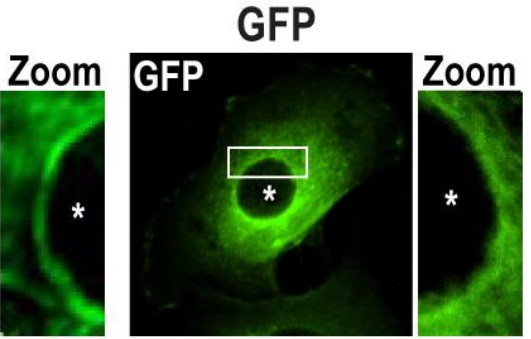

Zoom

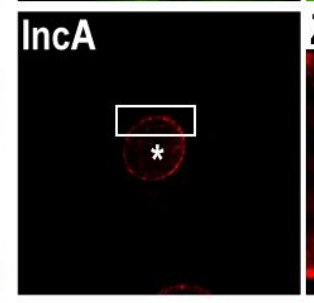

Zoom
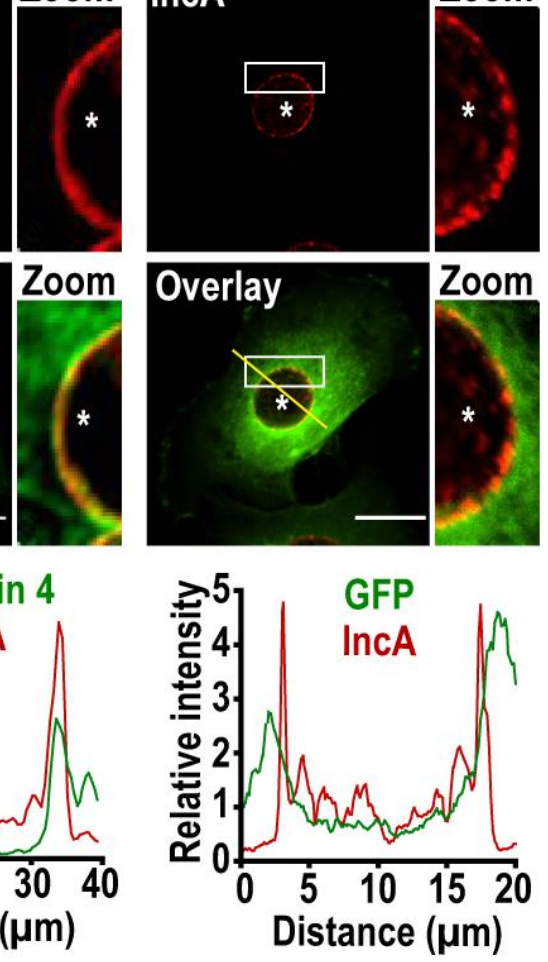

FIGURE 1: SNAP-23, Syntaxin 3, and Syntaxin 4 are recruited to the chlamydial inclusion. HeLa cells were infected with $C$. trachomatis at a MOI of 2 prior to being transfected with cDNA encoding (A) 3xFLAG-SNAP-23, (B) 3xFLAG-Syntaxin 3, (C) 3xFLAG-Syntaxin 4 or (D) GFP. At 24 $\mathrm{h}$ pi, the cells were fixed and labeled with anti-FLAG antibody (green) to label each SNARE and anti-IncA antibody (red) to identify the inclusion membrane. GFP-transfected cells (green) were only labeled with anti-IncA antibody (red). The boxed area of the inclusion membrane within each image is magnified to the right of each image (zoom). Asterisks denote inclusions. Scale bar $=20 \mu \mathrm{m}$. Line intensity scans (graphs) were conducted using ImageJ to determine if the FLAG or GFP signal was co-incident with IncA. Yellow line in the overlay image indicates the region of the line scan. Concomitant green (3xFLAG-SNARE or GFP) and red (IncA) peaks signify localization on the inclusion membrane.

inclusion membrane without globally affecting interactions between SNAP-23 and its heavy chains.

SNAP-23 and Syntaxin 4 are important for Chlamydia development

To test the importance of SNAP-23, Syntaxin 3, and Syntaxin 4 during infection, we depleted HeLa cells of either of these SNAREs using the CRISPR/Cas9 system (Fig. S3). These proteins were successfully knocked-down (KD) by at least $90 \%$ compared to the empty vector control (Fig. 2A). Note that all KD cells displayed the same growth kinetics as the empty vector control cell line, indicating that these
SNARE proteins are not required for cell growth and survival (Fig. S4).

Using these KD cells, we tested the impact of SNAP-23, Syntaxin 3, and Syntaxin 4 depletion on inclusion development. To do so, we infected the KD cell lines with $C$. trachomatis for $24 \mathrm{~h}$ or $46 \mathrm{~h}$. The cells were fixed and labeled with anti-IncA antibody to delineate the inclusion membrane, and the cells were visualized using immunofluorescence microscopy. As shown in Figure 2B, the inclusions that developed in the KD cell lines largely appear similar in size and shape compared to the empty vector control at $24 \mathrm{~h} \mathrm{pi}$. However, the inclusions that developed in Syntaxin 4 KD cells were $14 \%$ larger than those in empty vector con- 
trol cells $\left(172.2 \mu \mathrm{m}^{2}\right.$ versus $\left.151.1 \mu \mathrm{m}^{2}\right)$. While this difference is statistically significant, it remains modest. We did not detect differences in inclusion area in SNAP-23 or Syntaxin $3 \mathrm{KD}$ cells compared to the empty vector control cell line where the average inclusion size was $162.8 \mu^{2}$, $154.6 \mu \mathrm{m}^{2}$, and $151.1 \mu^{2}$, respectively (Fig. 2B, graph). Similar results were observed at $46 \mathrm{~h}$ pi (Fig. S5). Together, these data suggest that SNAP-23, Syntaxin 3, and Syntaxin 4 do not play a major role in inclusion development.
Next, we determined whether Chlamydia grown in SNAP-23, Syntaxin 3 or Syntaxin 4 KD cells were less fit than those grown in the control cell line by quantifying the amount of infectious progeny generated from each of the KD cell lines. Knocking down SNAP-23, Syntaxin 3 and Syntaxin 4 did not impact internalization and early inclusion development as evidence by the number of inclusions detected at $24 \mathrm{~h}$ pi (Fig. 2C). However, there was a $\sim 60 \%$ decrease in infectious progeny generated from the SNAP-23
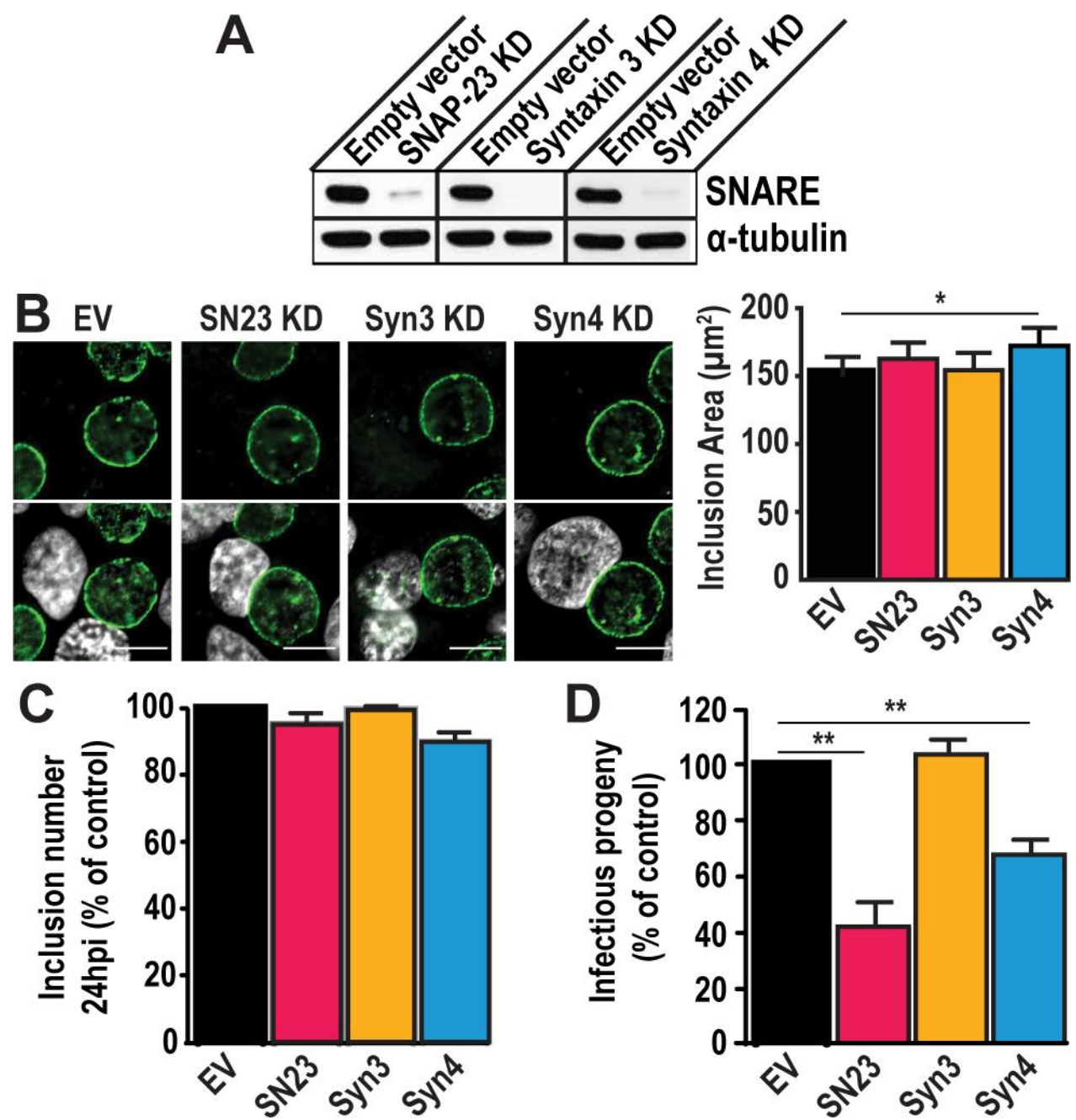

FIGURE 2: SNAP-23 and Syntaxin 4 regulate Chlamydia development. (A) Western blot analysis of protein levels in the indicated CRISPR knock down (KD) cell populations. SNARE corresponds to the t-SNARE in the KD cell line. Alpha-tubulin served as a loading control. (B) LeftThe KD cell lines were infected with $C$. trachomatis $L 2$ at a $\mathrm{MOI}$ of 0.5 for $24 \mathrm{~h}$, then fixed and stained with anti-IncA antibody (green). Hoechst was used to label DNA (gray). EV = empty vector control, SN23 $=$ SNAP-23, Syn3 $=$ Syntaxin 3, Syn4 $=$ Syntaxin $4, K D=k n o c k$ down. Scale bar $=10 \mu \mathrm{m}$. Right- Graph displays the average inclusion area from three independent experiments \pm the standard deviation. (C and $\mathrm{D})$ Cells were infected with $C$. trachomatis at a MOI of 0.5. (C) At $24 \mathrm{~h}$ pi, cells were fixed and stained with anti-MOMP antibody. The number of inclusions per well was calculated to determine internalization and early inclusion development, assuming that one inclusion corresponded to an infection inititated by a single EB. Graph denotes the average of at least three independent experiments \pm the standard deviation. For the purpose of comparison, the values obtained for the EV control were defined arbitrarily as $100 \%$ and represent $3.56 \times 10^{5} \pm 2.43 \times 10^{4}$ inclusion forming units (IFU)/ml. Values for the KD cells were then normalized to the EV control. (D) At $46 \mathrm{~h}$ pi, cells were lysed and serially diluted on a fresh monolayer of EV control cells. Twenty-four hours later, the cells were fixed and stained with anti- MOMP antibody. Only dilutions reflecting a $\mathrm{MOI}<1$ were counted. Graph denotes the average fold change in IFU at $\mathrm{T}=46 \mathrm{~h}$ compared to $\mathrm{T}=0 \mathrm{~h}$ of at least three independent experiments \pm the standard deviation. The fold change represents how many more IFU were present at $\mathrm{T}=46 \mathrm{~h}$ compared to $\mathrm{T}=$ $0 \mathrm{~h}$. For the purpose of comparison, the values obtained for EV control were defined arbitrarily as $100 \%$ and represent a fold change of $1,471.86 \pm 153.4$. Values for the KD cells were then normalized to the EV control. Asterisks denote significance, where $\left({ }^{*}\right)$ denotes a $p$ value $<0.05$ and $\left({ }^{* *}\right)$ denotes a $p$ value $<0.01$. 
KD cell line and a $\sim 35 \%$ decrease in the Syntaxin 4 KD cell line (Fig. 2D). These data demonstrate that while SNAP-23 and Syntaxin 4 are not required for the establishment of infection, they do play a role in the later stage of progeny development.

\section{SNAP-23 and Syntaxin 4 play a non-canonical role during Chlamydia infection}

The exocytic pathway is central to Chlamydia survival as the hijacking of Golgi-derived secretory vesicles provides much needed nutrients and resources for Chlamydia growth $[14,16]$. To identify the specific role of SNAP-23 and Syntaxin 4 during Chlamydia infection, we assessed whether Chlamydia targets the plasma membrane SNAREs to hijack secretory cargo destined for the plasma membrane.

To do so, we measured whether Chlamydia infection interfered with constitutive secretion in the host cell using a HeLa cell line (HeLa C1) that stably expresses EGFPtagged human growth hormone (hGH) containing tandem FKBP domains [43]. Under resting conditions, EGFP-hGH remained aggregated in the ER. Upon addition of $D / D$ solubilizer, a disaggregation reagent, EGFP-hGH was released from the ER and ultimately secreted into the extracellular medium. We tracked the constitutive secretion of EGFPhGH by measuring the EGFP signal that remained in the cell after the addition of the reagent to avoid dilution of the signal in the cell culture medium.

To test whether Chlamydia perturbs the constitutive secretory pathway, we infected HeLa C1 cells with C. trachomatis. At $22 \mathrm{~h} \mathrm{pi,} \mathrm{we} \mathrm{added} \mathrm{the} \mathrm{D/D} \mathrm{solubilizer} \mathrm{to} \mathrm{re-}$ lease $\mathrm{hGH}$ from the ER and measured the secretion of EGFP-hGH for $2 \mathrm{~h}$. We observed that the infected cells displayed similar kinetics of hGH secretion as the non-infected cells (Fig. S6A) and that EGFP-hGH was not detected inside of the inclusion in Chlamydia-infected cells (data not shown), indicating that hGH trafficking remains unperturbed during infection. These data are consistent with other model proteins used to track the secretory pathway during infection [17]. In light of these observations, the role of SNAP-23 and Syntaxin 4 during Chlamydia infection is likely independent of constitutive secretion. Note that after $22 \mathrm{~h}$ of infection, and before the addition of the D/D destabilizer, the EGFP signal was similar for infected and not infected cells (Fig. S6A, inset), indicating that the infection itself did not induce EGFP-hGH secretion or alter EGFP fluorescence.

Chlamydia also hijacks sphingomyelin (SM) and cholesterol from vesicles destined for the plasma membrane [13$17,44]$. Given the importance of the exocytic SNAREs in the fusion of secretory vesicles with the plasma membrane, we tested whether Chlamydia targets SNAP-23 and Syntaxin 4 to hijack sphingomyelin en route to the plasma membrane. To do so, we infected the KD cell lines with C. trachomatis for $20 \mathrm{~h}$. A fluorescent analog of ceramide, NBD-C6-ceramide, was added to the cell culture medium, before being chased for $6 \mathrm{~h}$. Ceramide is a SM precursor that is converted to SM in the Golgi and subsequently accumulates in the inclusion. Once the ceramide is processed by the host cell, the SM derived from it will retain the NBD signal and the excess ceramide is chased from the cell. In these experiments, SM localization was monitored by immunofluorescence microscopy and quantified by flow cytometry (Fig. S6B). We found that SM localized to the inclusion in all of the KD cell lines, indicating that there is no defect in SM trafficking to the inclusion in the absence of the plasma membrane SNAREs (Fig. S6B, images). Furthermore, the intensity of NBD fluorescence was similar in all of the KD cell lines compared to the empty vector control cells (Fig. S6B, graph), indicating that the amount of SM redirected to the inclusion is similar regardless of the $a b$ sence of the exocytic SNAREs.

Altogether, these data suggest that the role of SNAP-23 and Syntaxin 4 during Chlamydia infection is independent of their canonical roles in mediating membrane fusion at the plasma membrane.

\section{SNAP-23 and Syntaxin 4 play a critical role in LD homeo-} stasis during Chlamydia infection

In addition to mediating fusion events at the plasma membrane, SNAP-23 relocates from the plasma membrane and associates with cytoplasmic LDs where it participates in the homotypic fusion of LDs [45, 46]. Interestingly, Chlamydia infection increases the formation and production of LDs and LD-like structures have also been detected within the inclusion $[25,47]$. Thus, we investigated whether SNAP-23, Syntaxin 3 or Syntaxin 4 play a role in LD dynamics during Chlamydia infection.

First, we determined whether the depletion of SNAP23, Syntaxin 3 and Syntaxin 4 altered basal LD homeostatis in non-infected cells. Since HeLa cells do not store large quantities of LDs like adipocytes, we treated each KD cell line with oleic acid (OA) for $24 \mathrm{~h}$. $O A$ is a monounsaturated FA that is transported into the cell where it induces LD synthesis. The cells were then incubated with the fluorescent neutral lipid dye BODIPY 493/503 and their LD content was measured by flow cytometry (Fig. S7A). As expected, in all of the cell lines, the LD content of OA-treated cells was higher than untreated cells (Fig. S7B). Although the difference for the SNAP-23 KD cell line is statistically significant, it only corresponds to a modest $\sim 12 \%$ increase (Fig. S7C). As for Syntaxin 3 and Syntaxin 4, we observed a minor decrease in LD induction of $\sim 15 \%$ and $7 \%$, respectively. In total, these data indicate that knocking down SNAP-23, Syntaxin 3 and Syntaxin 4 has a limited effect on LD synthesis and that OA induced LDs to a similar extent in the SNAP-23, Syntaxin 3 and Syntaxin 4 KD cell lines compared to the empty vector control cell line.

Next, we investigated the impact of SNAP-23, Syntaxin 3 , and Syntaxin 4 depletion on LD production during infection. To do so, we infected the empty vector control cells, as well as each KD cell line, with a strain of $C$. trachomatis that constitutively expresses mCherry, which allowed us to distinguish between infected and non-infected cells. At 24 $\mathrm{h}$ pi, the cells were incubated with BODIPY and analyzed by flow cytometry to measure their LD content (Fig. 3A). In each of the cell lines, the infected cells displayed higher levels of BODIPY staining than the non-infected popula- 
tions, confirming that Chlamydia infection triggers an increase in neutral lipid content (Fig. 3B and [47]). Next, we compared the degree to which Chlamydia increases neutral lipid content in each of the KD cell lines. Compared to the empty vector control cell line, we observed a $71 \%$ and $\sim 49 \%$ higher induction of LD content following infection in SNAP-23 and Syntaxin 4 KD cells, respectively (Fig. 3C). In contrast, the induction of LDs by Chlamydia in Syntaxin 3 $\mathrm{KD}$ cells was $\sim 1 \%$ lower than the empty vector control. These data indicate that SNAP-23 and Syntaxin 4, but not Syntaxin 3, are involved in LD homeostasis during infection. Furthermore, since the induction of LDs by OA-treatment in non-infected cells (Fig. S7C) was not affected by the absence of SNAP- 23 or Syntaxin 4, it is unlikely that the in- crease in LD content during infection (Fig. $3 C$ ) is due to a global dysregulation in LD synthesis. Rather, the role of SNAP-23 and Syntaxin 4 in the regulation of LDs is specific to Chlamydia infection.

During infection, Chlamydia internalizes LD-like structures into the inclusion lumen [25]. Thus, we determined whether the increase in LD content in SNAP-23 and Syntaxin $4 \mathrm{KD}$ cells was due to an inability to internalize LDs into the inclusion. To accomplish this, we visualized BODIPYstained structures inside of IncA-labeled inclusions generated in SNAP-23 and Syntaxin 4 KD cell line, compared to empty vector control cells. Using confocal microscopy (Fig. 3D) and 3-dimensional reconstruction (Fig. S8), we detected LD-like structures within inclusions generated in both of
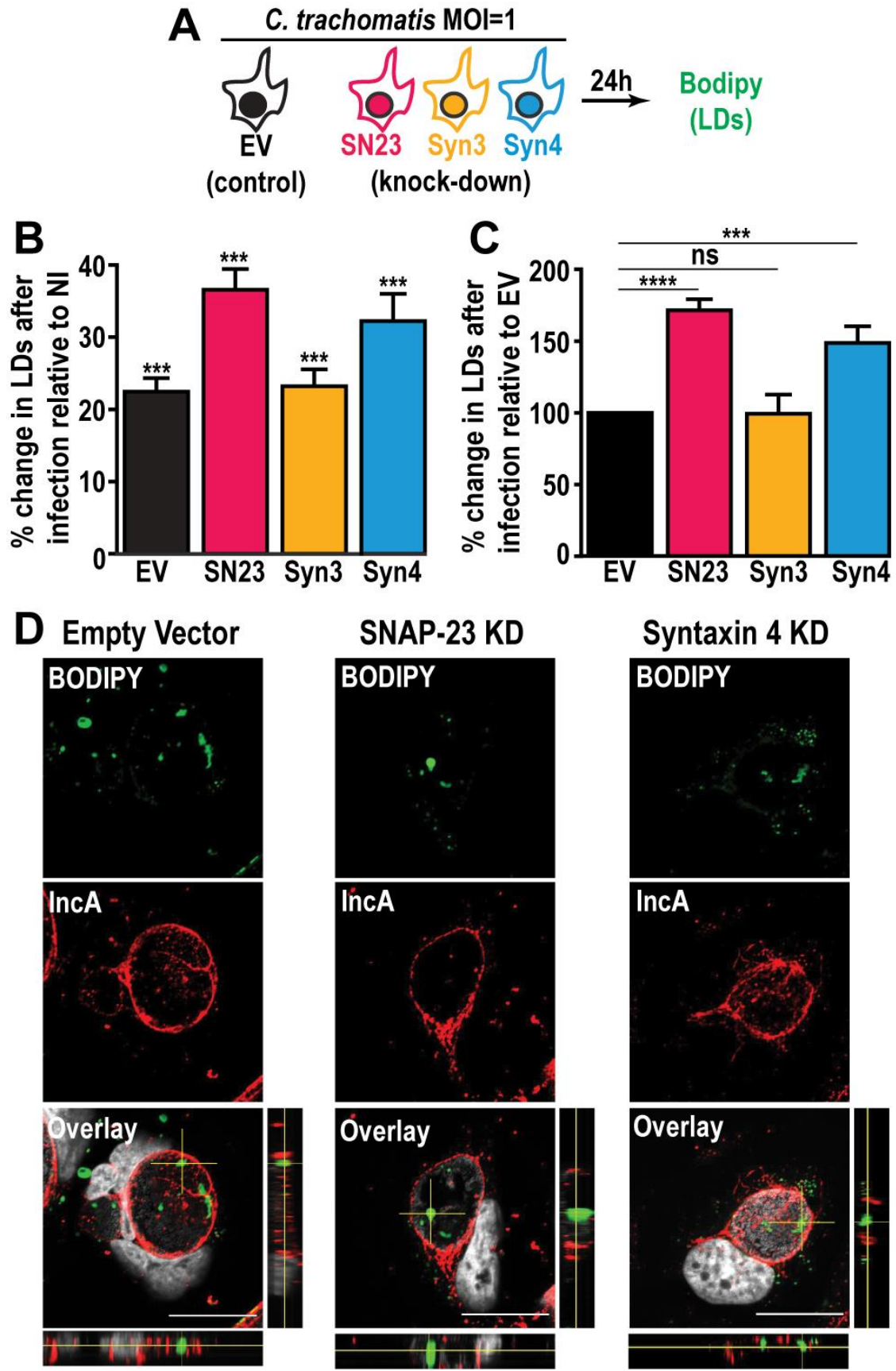

FIGURE 3: Depletion of SNAP-23 and Syntaxin 4 increases LD content during Chlamydia infection without affecting LD internalization into the inclusion lumen. (A) Experimental design. SN23 = SNAP-23, Syn3 = Syntaxin 3, Syn4 = Syntaxin 4, LDs = lipid droplets, $\mathrm{MOI}=$ multiplicity of infection. (B and C) Cells were either infected with $\mathrm{mCherry}$-expressing $C$. trachomatis $\mathrm{L} 2$ at a MOI of 1 or mock-infected with DMEM for $24 \mathrm{~h}$. The cells were then stained with BODIPY and fixed. BODIPY intensity was measured by flow cytometry. For the infected samples only the mCherry-positive population (infected cells) was measured. (B) Graph represents the average percent increase in BODIPY staining relative to noninfected cells from at least three independent experiments \pm the standard deviation. Asterisk $\left({ }^{* * *}\right)$ denotes a $p$ value < 0.001 . (C) Graph represents the average increase in BODIPY staining relative to infected empty vector control cells from at least three independent experiments \pm the standard deviation. The percent increase in BODIPY staining following infection for the empty vector control cell line was arbitrarily set at $100 \%$ and represents $121.41 \% \pm$ 4.92. Values for the KD cells were then normalized to the EV control. Asterisk $(* * *)$ denotes a $p$ value $<0.001$ and $(* * * *)$ denotes a $p$ value $<0.0001$. ns $=$ not significant. (D) The indicated cell lines were infected with $C$. trachomatis $\mathrm{L} 2$ at a $\mathrm{MOI}$ of 0.5 for $30 \mathrm{~h}$. The cells were then fixed and stained with anti-IncA antibody (red) and BODIPY 493/503 (green). Hoechst was used to label DNA (gray). Images are taken from a single plane of confocal z-stacks. Orthogonal $X Z$ and $Y Z$ views are shown next to and below the overlay image, respectively. Scale bar $=20 \mu \mathrm{m}$. KD $=$ knock down. 
the KD cell lines, indicating that internalization of LDs into the lumen of the inclusion was intact and that these SNAREs are not essential for this process.

The availability of FAs, which are incorporated into LDs, affects Chlamydia growth and development [48]. Since LD homeostasis is dysregulated during infection in SNAP-23 and Syntaxin 4 KD cells, we assessed the impact of increasing host cell FAs on Chlamydia-induced LDs in the SNAP-23 and Syntaxin 4 KD cell lines. This was tested in two configurations: (1) OA was added at the time of infection to assess the impact of supplemental LD synthesis on Chlamydiainduced LDs (Fig. 4A, schematic) and (2) OA was added 24 $\mathrm{h}$ prior to infection as well as at the time of infection to test the impact of increasing LD levels prior to infection (Fig. 4B, schematic). The addition of $O A$ at the time of infection resulted in a substantial $\sim 70 \%$ and $\sim 67 \%$ increase in LD content compared to the empty vector control cell line in SNAP-23 and Syntaxin 4 KD cells, respectively (Fig. 4A). This effect was further enhanced when cells were pretreated with OA $24 \mathrm{~h}$ prior to the infection. In these conditions, we observed a $\sim 98 \%$ and $\sim 74 \%$ increase in neutral lipid content above the empty vector control cell line in SNAP-23 and Syntaxin 4 KD cells, respectively, compared to $\sim 2 \%$ in the Syntaxin 3 KD cell line (Fig. 4B). Together, these results demonstrate that both, SNAP-23 and Syntaxin 4, control LD homeostasis specifically during Chlamydia infection and that this effect can be boosted with exogenous FAs.
The dysregulation of LD homeostasis caused by knocking down SNAP-23 and Syntaxin 4 revealed an important pathway during infection as it correlates with a defect in Chlamydia development (Fig. 2D). A potential explanation for the decrease in infectious progeny in the absence of SNAP-23 and Syntaxin 4 is that the increase in LD content during infection may be toxic to Chlamydia. To assess this possibility, we used OA to artificially increase the LD content in HeLa cells prior to infection. We then quantified early inclusion development at $24 \mathrm{~h}$ pi and the generation of infectious progeny at $46 \mathrm{~h}$ pi. OA treatment did not interfere with internalization and early inclusion development at $24 \mathrm{~h}$ pi (Fig. S9A), nor did it impact the generation of infectious progeny (Fig. S9B). These data indicate that simply increasing the LD content is not sufficient to interfere with Chlamydia growth and highlights a specific SNARE-dependent LD pathway induced by Chlamydia infection.

\section{DISCUSSION}

LDs are heterogeneous storage organelles at the center of cellular lipid homeostasis [49]. They have a unique structure, consisting of a neutral lipid core surrounded by a phospholipid monolayer and have distinct protein compositions that likely reflect diverse functions within the cell [50]. LDs are dynamic organelles, that expand and contract according to the metabolic requirements of the cell. LDs originate from the ER, where they acquire most of their
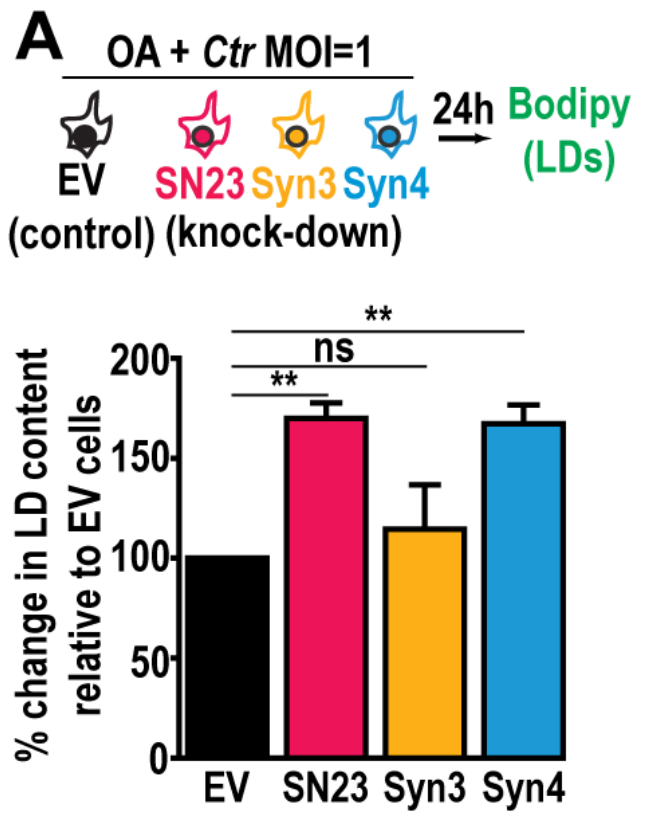
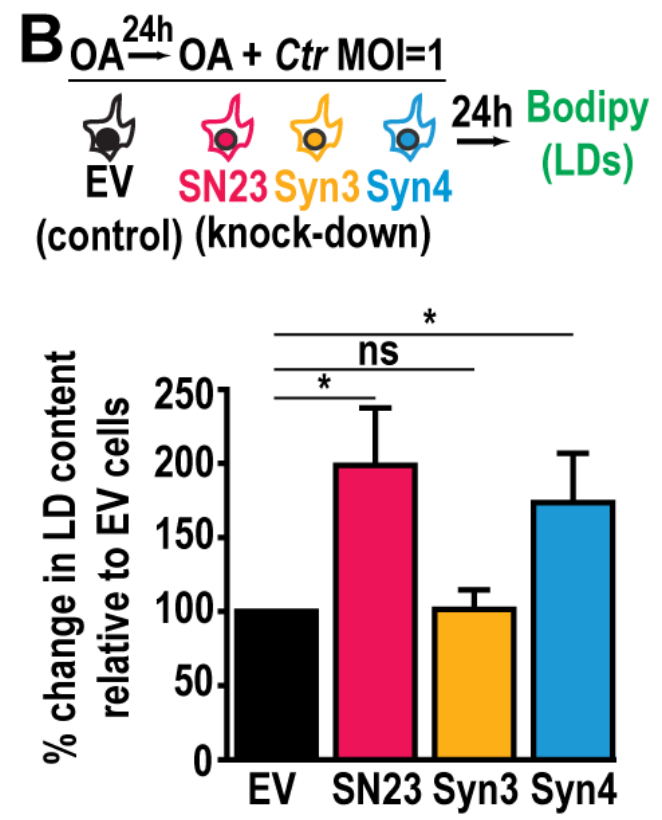

FIGURE 4. The addition of OA enhances the induction of LD content in SNAP-23 or Syntaxin 4 knock down cells during Chlamydia infection. Cells were (A) infected in the presence of OA for $24 \mathrm{~h}$, or (B) pre-treated with OA for $24 \mathrm{~h}$ before infection. The cells were then stained with BODIPY, fixed, and the BODIPY intensity was measured by flow cytometry. For the infected populations, only the mCherry-positive cells were measured. Graphs represent the average increase in BODIPY staining following infection relative to empty vector control cells from at least three independent experiments \pm the standard deviation. The percent increase in BODIPY staining following infection for the empty vector control cell line was arbitrarily set at $100 \%$ and represents (A) $174.72 \% \pm 17.61 \%$ and (B) $181.63 \% \pm 30.55 \%$. Values for the KD cells were then normalized to the EV control. Asterisk $\left({ }^{*}\right)$ denotes a $p$ value $<0.05$ and $(* *)$ denotes a $p$ value $<0.01$. ns $=$ not significant. EV $=$ empty vector control, SN23 = SNAP-23, Syn3 = Syntaxin 3, Syn4 = Syntaxin 4, LDs = lipid droplets. MOI = multiplicity of infection. Ctr = Chlamydia trachomatis. 
constituent molecules [50,51]. After budding from the ER, LDs can grow through direct transfer of triacylglycerol from the ER membrane, local lipid synthesis [52], or through homotypic fusion [53]. LD homotypic fusion requires host SNARE proteins including SNAP-23, Syntaxin 5, and VAMP4 [45]. Although the involvement of Syntaxin 4 in the LD pathway has not been previously shown, here we demonstrate that the loss of SNAP-23 or Syntaxin 4 results in the significant enhancement of Chlamydia-induced LDs. This effect is specific to Chlamydia infection since the induction of LDs by OA results in comparable levels of LDs in the empty vector control, SNAP-23, and Syntaxin $4 \mathrm{KD}$ cell lines.

One possibility is that the increase in LD content observed in SNAP-23 and Syntaxin 4 KD cells during infection is due to a decrease in LD consumption by Chlamydia in these cells. $C$. trachomatis has been shown to translocate neutral lipids into the inclusion lumen $[25,47]$. As the infection progresses, the amount of LD-like structures inside of the inclusion lumen appears to remain constant, suggesting that Chlamydia consumes these LDs as soon as they are engulfed [25]. C. trachomatis may require SNAP23 on the inclusion membrane in order to hijack them, possibly through the recruitment of its cognate t-SNARE Syntaxin 4. If so, the loss of these SNAREs would impact the recruitment of LDs into the inclusion and ultimately impair the lipid composition of Chlamydia. Although we cannot exclude this possibility, immunofluorescence microscopy shows that LD-like structures are present inside of inclusions formed in SNAP-23 and Syntaxin 4 KD cells (Fig. 3D and S8), suggesting that some level of engulfment remains and that this alone does not account for the significant growth defect observed in these cell lines.

An alternative possibility is that $C$. trachomatis infection stimulates a pathway in which SNAP- 23 and Syntaxin 4 control the formation and/or hijacking of a particular subset of LDs. Chlamydia-induced LDs likely have a distinct composition from OA-induced LDs. In fact, it has been shown that Chlamydia secretes LD-binding proteins called Lda [47]. While Lda1 and Lda3 bind mammalian LDs in the cytosol, Lda2 only binds LDs induced during infection, highlighting the distinct composition of LDs generated during Chlamydia infection. SNAP-23 and Syntaxin 4 could influence the formation of these types of Chlamydia-induced LDs. Ultimately, their depletion would lead to the accumulation of LDs that are unable to be metabolized by Chlamydia, which would then negatively impact Chlamydia fitness. This hypothesis is supported by several observations: i) SNAP-23 and Syntaxin 4 are specifically involved in the formation of Chlamydia-induced but not OA-induced LDs, supporting the existence of multiple LD synthesis pathways (Fig. 3B, 4, and S7); ii) the decrease in infectious progeny generated in SNAP-23 and Syntaxin $4 \mathrm{KD}$ cells demonstrate that Chlamydia replication is impaired (Fig. 2D), even though LD-like structures are observed inside the inclusion lumen (Fig. 3D and S8); and iii) Chlamydia grown in cells in which LDs were induced by OA are not replication defective (Fig. S9), indicating that a surplus of OAinduced LDs is not toxic.
In summary, our data show that the loss of both SNAP23 and Syntaxin 4 results in an aberrant increase in LD production during Chlamydia infection. Chlamydia, in turn, exhibits a decrease in infectious progeny, likely due to the altered composition of the LDs generated in these cells in the absence of these two SNAREs. Additional studies are necessary to compare the composition of Chlamydiainduced LDs versus OA-induced LDs. Ultimately, identifying the molecular components involved in this pathway will shed light on how both of these SNAREs regulate LD homeostasis during Chlamydia infection.

\section{MATERIALS AND METHODS \\ Cell culture and Chlamydia strains}

HeLa cells (ATCC CCL-2) were cultured in Dulbecco's modified Eagle's medium (DMEM) supplemented with $10 \%$ fetal bovine serum (FBS), $2 \mathrm{mM}$ L-glutamine, $1 \mathrm{mM}$ sodium pyruvate, MEM non-essential amino acids and $10 \mu \mathrm{g} / \mathrm{mL}$ gentamicin. HeLa C1 cells expressing human growth hormone fused to EGFP and tandem mutated FKBP domains were a gift from Dr. Andrew Peden (University of Sheffield) [43]. C. trachomatis serovar L2 strain 434/Bu and a recombinant strain constitutively expressing mCherry were kindly provided by $\mathrm{Dr}$. T. Hackstadt ( $\mathrm{NIH}$, NIAID) [54].

\section{Antibodies and dyes}

The following primary antibodies were used: rabbit anti-IncA (gift from T. Hackstadt), goat anti-MOMP (Virostat), rabbit anti-Syntaxin 3 (Synaptic Systems), rabbit anti-Syntaxin 4 (Sigma), rabbit anti-SNAP-23 (Sigma), mouse anti-alpha tubulin (Sigma), mouse anti-FLAG (Sigma, M2), chicken anti-HSP70 (StressMarq). Goat anti-rabbit IgG-Alexa Fluor 488, goat antirabbit IgG-Alexa Fluor 647, goat anti-mouse IgG-Alexa Fluor 488, goat anti-rabbit IgG-Alexa Fluor 555, donkey anti-goat IgG-Alexa Fluor 488, donkey anti-rabbit IgG-, anti-mouse IgG-, anti-goat IgG-, and anti-chicken IgY-horseradish peroxidase (HRP)-conjugated secondary antibodies, Hoechst, and NBD-C6ceramide were purchased from Invitrogen. BODIPY 493/503 and CFSE Cell Proliferation Kit were purchased from ThermoFisher.

\section{Plasmid construction and genome editing}

Polymerase chain reactions (PCR) were performed with High Fidelity polymerase (Accuris) according to manufacturer's protocols. FastDigest restriction enzymes, FastAP phosphatase, and T4 DNA ligase were purchased from ThermoFisher. The $\mathrm{DH} 5 \alpha$ E. coli strain was used for plasmid amplification and isolation. All primers are listed in Table S1. Human SNAP-23 was amplified from pEGFP-human SNAP-23 (Addgene) using the oligonucleotides FO1294 and FO1296. Rat Syntaxin 3 was amplified from rat Syntaxin 3-EGFP (FD269) using the oligonucleotides FO1327 and FO1328. Rat Syntaxin 4 was amplified from rat Syntaxin 4-EGFP (FD270) using the oligonucleotides FO1329 and FO1330. Note that both rat Syntaxin 3 and Syntaxin 4 are $97.22 \%$ and $89.23 \%$ identical to human Syntaxin 3 and Syntaxin 4, respectively (Fig. S10) and are commonly used to replace human Syntaxins $[55,56]$. PCR fragments were cloned into the EcoRI and Xhol sites of pCMV-Tag2B (gift from Paul Roche, NIH), which was modified to contain a 3xFLAG tag instead of a single FLAG tag. DNA sequences were confirmed by Sanger sequencing (GenScript). 
Guide RNA and confirmation primers were designed using the exon-intron structures available at GenBank. These guide RNAs were then analysed for their efficiency and theoretical off-target effects, using the CRISPOR [57] and the Broad Institute sgRNA designer [58] databases with default cut-offs. Only guideRNAs with appropriate scores from these databases were selected. Guide RNAs were cloned into the pSpCas9(BB)2A-GFP (PX458) vector (provided by S. Kim) and confirmed by Sanger sequencing. HeLa cells were seeded in $100 \mathrm{~mm}$ tissue culture dishes $24 \mathrm{~h}$ prior to being transfected with $6 \mu \mathrm{g}$ of plasmid at a $1 \mu \mathrm{g}: 1 \mu \mathrm{l}$ ratio using the Continuum Transfection Reagent (Gemini Bio-products) and incubated for $24 \mathrm{~h}$ at $37^{\circ} \mathrm{C}$ and $5 \% \mathrm{CO}_{2}$. Cells transfected with the vector encoding only Cas9-GFP (no guide RNA) were used as a control. The cells were then sorted based on GFP expression, using flow cytometry (BD FACSAria II). To confirm successful targeting of the guide RNA and Cas9 cleavage, genomic DNA was extracted from each cell population and a region corresponding to the predicted Cas9 cut site was PCR amplified using the confirmation primers. For each reaction, $2 \mu \mathrm{g}$ genomic DNA was used. The full PCR reaction was run on a $1 \%$ agarose gel and the amplicon band was cut and purified. Cas9 activity was assessed by digesting the amplicon with $10 \mathrm{U}$ of T7E1 endonuclease at $37^{\circ} \mathrm{C}$ for $1 \mathrm{~h}$ (Fig. S3). Cell lines with productive Cas9 activity were analyzed by Western blot to determine the level of target protein knock down (see below). The protocol was repeated until protein levels were reduced by at least $90 \%$. Each knock down cell line was maintained as a population to prevent any potential off-target or clonal effects.

\section{Western blotting}

Samples were lysed in cold lysis buffer (50 mM Tris, $100 \mathrm{mM}$ $\mathrm{NaCl}, 2 \mathrm{mM} \mathrm{MgCl}$, $1 \%$ Nonidet- P40, 10\% glycerol, pH 7.5 supplemented with $2 \mathrm{mM}$ phenylmethanesulfonyl fluoride, $2 \mu \mathrm{M}$ pepstin A, $10 \mu \mathrm{M}$ leupeptin, $10 \mathrm{mM} \mathrm{NaF}$, and $5.4 \mathrm{mM}$ $\mathrm{Na}_{3} \mathrm{VO}_{4}$ ) for $1 \mathrm{~h}$ on ice. Lysates were clarified by centrifugation and protein concentrations were measured using the Pierce $660 \mathrm{~nm}$ Protein Assay (ThermoFisher). The samples were diluted in loading buffer ( $50 \mathrm{mM}$ Tris, $2 \%$ sodium dodecyl sulfate, $10 \%$ glycerol, $0.3 \mathrm{mM}$ bromophenol blue, $2.5 \%$ $\beta$-mercaptoethanol), separated on $12 \%$ Tris-glycine SDS-PAGE gels, and transferred at $100 \mathrm{~V}$ to polyvinylidene difluoride membrane (Millipore) for $1 \mathrm{~h}$ at $4^{\circ} \mathrm{C}$. The membranes were rinsed with wash buffer ( $25 \mathrm{mM}$ Tris, $150 \mathrm{mM} \mathrm{NaCl}, \mathrm{pH}$ 7.5, $0.1 \%$ Tween-20) and blocked with wash buffer containing $3 \%$ bovine serum albumin (BSA) and $0.05 \% \mathrm{NaN}_{3}$ for $1 \mathrm{~h}$ at room temperature (RT). Membranes were probed with the indicated primary antibodies diluted in the blocking buffer overnight at $4^{\circ} \mathrm{C}$. The membranes were then washed several times with wash buffer and incubated with HRP-conjugated secondary antibodies diluted in wash buffer containing $0.5 \%$ milk for $1 \mathrm{~h}$ at RT. Following several washes, the blots were revealed with SuperSignal West Dura Extended Duration Substrate (ThermoFisher) and autoradiography film.

\section{Immunofluorescence staining}

Cells were fixed either with ice-cold methanol or $4 \%$ paraformaldehyde (PFA) for 20 min at RT and washed in IF buffer (0.9 mM CaCl$, 0.5 \mathrm{mM} \mathrm{MgCl}, 150 \mathrm{mM} \mathrm{NaCl}, 100 \mathrm{mM}$ glycine, $25 \mathrm{mM}$ HEPES, pH 7.5). The cells were permeabilized and blocked in blocking buffer $(0.1 \%$ Triton X-100, $10 \%$ normal goat serum in IF buffer) for $30 \mathrm{~min}$ at RT. Coverslips were then incubated with rabbit anti-IncA antibody (1:500) and/or mouse anti-FLAG (M2 Sigma, 1:100) diluted in blocking buffer for $1 \mathrm{~h}$ at RT. The coverslips were then washed several times with IF Buffer containing $0.1 \%$ Triton X-100 and incubated with goat anti-rabbit IgG Alexa Fluor 555 and goat anti-mouse IgG Alexa Fluor 488-conjugated secondary antibodies (Invitrogen, 1:500) and $1 \mu \mathrm{g} / \mathrm{ml}$ Hoechst (Invitrogen) diluted in blocking buffer for $1 \mathrm{~h}$ at RT. Coverslips were washed with IF buffer and mounted with Prolong Glass Antifade reagent (Invitrogen).

\section{SNARE recruitment to the inclusion}

HeLa cells were seeded onto coverslips in a 24-well plate at a density of $3 \times 10^{4}$ cells per well $24 \mathrm{~h}$ prior to infection. The cells were infected with $C$. trachomatis $\mathrm{L} 2$ at a multiplicity of infection (MOI) of 2 by centrifugation at $1,000 \mathrm{xg}$ for $1 \mathrm{~h}$ at $4^{\circ} \mathrm{C}$ and then transitioned to $37^{\circ} \mathrm{C}$ and $5 \% \mathrm{CO}_{2}$ for $3 \mathrm{~h}$. The infected cells were then transfected with $25 \mathrm{ng}$ of each plasmid supplemented with $225 \mathrm{ng}$ of empty pcDNA3.1+ plasmid at a $1 \mu \mathrm{g}$ of DNA:1 $\mu$ l of Continuum transfection reagent (Gemini Bioproducts) ratio and incubated for an additional $21 \mathrm{~h}$ at $37^{\circ} \mathrm{C}$ and $5 \% \mathrm{CO}_{2}$. At $24 \mathrm{~h}$ pi the cells were fixed and stained as described above. Images were acquired with a Nikon A1R+ confocal microscope with $60 x$ oil immersion lens and Nikon NIS Elements software. Contrast enhancement and image cropping, as well as line scans were conducted using Image ( $\mathrm{NIH}$ ).

\section{Inclusion size analysis}

HeLa cells were seeded onto coverslips at a density of $1 \times 10^{5}$ cells per well in a 24 -well plate $24 \mathrm{~h}$ prior to infection. The cells were infected with $C$. trachomatis $L 2$ at a $\mathrm{MOI}$ of 0.5 by centrifugation at $1,000 \mathrm{xg}$ for $1 \mathrm{~h}$ at $4^{\circ} \mathrm{C}$. The cells were then transitioned to $37^{\circ} \mathrm{C}$ and $5 \% \mathrm{CO}_{2}$ for $24 \mathrm{~h}$ or $46 \mathrm{~h}$. The cells were fixed and stained as described above. Images were acquired using a Nikon TiE inverted immunofluorescence microscope with a 60x oil immersion lens and Nikon NIS Elements AR 4.2 software. Contrast enhancement and image cropping were performed using Image $(\mathrm{NIH})$. Inclusion area was acquired by tracing the outline of the inclusion using NIS Elements software. A minimum of 100 inclusions per sample were measured for each experiment.

\section{Progeny analysis}

HeLa cells were seeded at a density of $1 \times 10^{5}$ cells per well in a 24 -well plate $24 \mathrm{~h}$ prior to infection. Cells were infected with C. trachomatis $\mathrm{L} 2$ at a $\mathrm{MOI}$ of 0.5 by centrifugation at $1,000 \mathrm{xg}$ for $1 \mathrm{~h}$ at $4^{\circ} \mathrm{C}$. At $24 \mathrm{~h} \mathrm{pi}$, one set of cells were fixed and stained with anti-IncA antibody as described above to determine the inclusion forming units (IFU) at infection ( $T=0 \mathrm{~h}$ ). At $46 \mathrm{~h} \mathrm{pi}$, the other set of cells were lysed in sterile water. The lysates were serially diluted in HBSS and used to infect a new monolayer of empty vector control cells. The cells were then fixed $24 \mathrm{~h}$ pi and labeled with anti-IncA antibody as described above. Images were acquired and analyzed using a Nikon TiE inverted immunofluorescence microscope with 20x lens and Nikon NIS Elements AR 4.2 software. Image processing was conducted using ImageJ (NIH). Each condition was prepared in triplicate for each experiment, and a minimum of 20 images per well were counted. The number of inclusions in each well was then calculated considering the dilution factor and the surface area of the well. The fold change in IFU was calculated by dividing the number of IFU obtained from $\mathrm{T}=46 \mathrm{~h}$ by the 
IFU at $\mathrm{T}=0 \mathrm{~h}$. The resulting ratio denotes how many more IFU were found at $\mathrm{T}=46 \mathrm{~h}$ compared to $\mathrm{T}=0 \mathrm{~h}$. For comparison purposes, all values were then normalized to the empty vector values.

\section{Constitutive secretion assay}

HeLa C1 cells were seeded at a density of $8.8 \times 10^{3}$ cells per well in a 96-well plate $24 \mathrm{~h}$ prior to infecting with $C$. trachomatis L2 at a $\mathrm{MOI}$ of 2 . The infection was synchronized by centrifugation at $1,000 \mathrm{xg}$ for $1 \mathrm{~h}$ at $4^{\circ} \mathrm{C}$ and the cells were incubated at $37^{\circ} \mathrm{C}$ and $5 \% \mathrm{CO}_{2}$ for $22 \mathrm{~h}$. EGFP human growth hormone (hGH) was released from the ER with $0.7 \mu \mathrm{M} D / D$ solubilizer dissolved in ethanol (ClonTech) or ethanol alone (control). At the indicated time points, the wells were washed with HBSS to remove secreted EGFP-hGH. The EGFP-hGH remaining in the cells was measured on SpectraMax M2 spectrophotometer (Molecular Devices). EGFP was excited at $460 \mathrm{~nm}$ and emission was read at $510 \mathrm{~nm}$. HeLa cells not expressing EGFP-hGH were used to control for autofluorescence, which was subtracted from all wells containing HeLa C1 cells. EGFP-hGH secretion was calculated using the following formula:

\section{$\%$ EGFP-hGH secretion $=100 \%-[(A-A 1) /(B-B 1) \times 100]$}

Where, $A=$ EGFP intensity of HeLa C1 well containing D/D solubilizer, $A 1=$ EGFP intensity of HeLa well containing $D / D$ solubilizer, $B=$ EGFP intensity of HeLa C1 well containing ethanol, B1= EGFP intensity of HeLa well containing ethanol.

\section{Ceramide acquisition}

HeLa cells were seeded onto coverslips or onto wells at a density of $1 \times 10^{5}$ cells per well in a 24 -well plate $24 \mathrm{~h}$ prior to infection. Cells were infected with $C$. trachomatis $L 2$ constitutively expressing mCherry at a $\mathrm{MOI}$ of 0.5 for flow cytometry or with WT C. trachomatis $\mathrm{L} 2$ at a $\mathrm{MOI}$ of 1 for immunofluorescence analysis. The infection was synchronized by centrifugation at $1,000 \mathrm{xg}$ for $1 \mathrm{~h}$ at $4^{\circ} \mathrm{C}$. The cells were transitioned to $37^{\circ} \mathrm{C}$ and $5 \% \mathrm{CO}_{2}$ for $20 \mathrm{~h}$. The cells were incubated with $5 \mu \mathrm{M}$ NBD-C6ceramide for $30 \mathrm{~min}$ at $37^{\circ} \mathrm{C}$. The cells were washed with HBSS and incubated with $0.34 \%$ FA-free BSA in serum-free DMEM for $6 \mathrm{~h}$ to allow for back-exchange. For microscopy analysis, the coverslips were washed several times with HBSS, stained with

$1 \mathrm{\mu g} / \mathrm{ml}$ of Hoechst (Invitrogen) for $5 \mathrm{~min}$ at $37^{\circ} \mathrm{C}$ and mounted for live cell imaging with HBSS. Images were acquired and processed using a Nikon TiE inverted immunofluorescence microscope with a $60 x$ oil immersion lens and Nikon NIS Elements AR 4.2 software. Contrast enhancement and image cropping were conducted using ImageJ (NIH). For flow cytometry, the cells were trypsinized into suspension and fixed in $4 \%$ PFA in HBSS for 10 min at RT. Each sample was resuspended in FACS Buffer ( 25 mM HEPES, 1 mM EDTA, 1\% FBS in phosphate buffered saline [PBS], $\mathrm{pH}$ 7.0) and analyzed on LSRFortessa flow cytometer (BD Biosciences).

\section{Lipid droplet quantification assay}

HeLa cells were seeded at a density of $6 \times 10^{4}$ cells per well in a 24-well plate. To pre-treat cells with $O A$, cells were incubated with $200 \mu \mathrm{M}$ of OA diluted in PBS containing 10\% FA-free BSA for $24 \mathrm{~h}$. DMSO was used as the control. The cells were then infected with $C$. trachomatis L2 constitutively expressing mCherry at a $\mathrm{MOI}$ of 1 by centrifugation at $1,000 \mathrm{xg}$ for $1 \mathrm{~h}$ at $4^{\circ} \mathrm{C}$ or mock-infected with DMEM. For OA treatment at the time of infection, $200 \mu \mathrm{M}$ of OA or DMSO was added after centrifugation. The cells were then transitioned to $37^{\circ} \mathrm{C}$ and $5 \% \mathrm{CO}_{2}$ for $24 \mathrm{~h}$. The cells were stained with $50 \mu \mathrm{M}$ BODIPY $493 / 503$ (ThermoFisher) for $30 \mathrm{~min}$ at $37^{\circ} \mathrm{C}$ and washed several times with HBSS. The cells were trypsinized into a single cell suspension and fixed in 4\% PFA in HBSS for 10 min at RT. Each sample was then resuspended in FACS Buffer and analyzed on a LSRFortessa flow cytometer (BD Biosciences). For each cell line, a ratio was obtained for the BODIPY intensity in the corresponding control cells with that of the treated cells (i.e. not infected:infected or DMSO:OA). This ratio for the EV control cells was considered $100 \%$ and all values were normalized to the EV ratio for each experiment. Each experiment was independently performed at least 3 times in triplicate.

\section{LD analysis inside inclusion}

HeLa cells were seeded at a density of $4 \times 10^{4}$ cells per coverslip in a 24-well plate $24 \mathrm{~h}$ prior to infection. The cells were infected with $C$. trachomatis $\mathrm{L} 2$ at a $\mathrm{MOI}$ of 0.5 by centrifugation at $1,000 \mathrm{xg}$ for $1 \mathrm{~h}$ at $4^{\circ} \mathrm{C}$. The cells were then transitioned to $37^{\circ} \mathrm{C}$ and $5 \% \mathrm{CO}_{2}$. At $30 \mathrm{~h}$ pi, cells were fixed with $3 \% \mathrm{PFA}$ and $0.025 \%$ of glutaraldehyde in PEMS buffer $(80 \mathrm{mM}$ PIPES, $\mathrm{pH}$ 7.0, $5 \mathrm{mM}$ EGTA, $2 \mathrm{mM} \mathrm{MgCl}$, $50 \mathrm{mM}$ sucrose) for $20 \mathrm{~min}$ at RT. The coverslips were washed with IF buffer containing 100 $\mathrm{mM}$ glycine. The cells were permeabilized with PBS containing $0.2 \mathrm{M}$ glycine, $30 \mathrm{mg} / \mathrm{mL}$ BSA and $0.01 \%$ saponin for $45 \mathrm{~min}$ at RT and then blocked with blocking buffer (10\% horse serum, $0.05 \% \mathrm{NaN}_{3}$ in IF Buffer) for $30 \mathrm{~min}$ at RT. Coverslips were washed with IF buffer and then incubated with anti-IncA antibody (1:500) diluted in PBS containing 0.01\% saponin and 1 $\mathrm{mg} / \mathrm{mL}$ of BSA for $1 \mathrm{~h}$ at RT. The coverslips were then washed several times with IF Buffer and incubated with goat antirabbit IgG Alexa Fluor 647-conjugated secondary antibody (Invitrogen, 1:500), $1 \mu \mathrm{g} / \mathrm{mL}$ Hoechst (Invitrogen) and $12.5 \mu \mathrm{M}$ BODIPY 493/503 (ThermoFisher) in PBS containing 0.01\% saponin and $1 \mathrm{mg} / \mathrm{mL}$ of BSA for $1 \mathrm{~h}$ at RT. Coverslips were mounted with Prolong Glass Antifade reagent (Invitrogen). Images were acquired with a Nikon A1R+ confocal microscope with 60x oil immersion lens and Nikon NIS Elements software. Contrast enhancement and image cropping, as well as 3D reconstruction were conducted using ImageJ ( $\mathrm{NIH})$.

\section{Cell Division Assay}

HeLa cells were stained with $5 \mathrm{mM}$ carboxyfluorescein succinimidyl ester (CFSE) (Cell Trace Cell Proliferation Kit, Invitrogen) and seeded in 6-well plates at $1 \times 10^{5}$ cells per well and incubated at $37^{\circ} \mathrm{C}$ with $5 \% \mathrm{CO}_{2}$ for $24 \mathrm{~h}, 48 \mathrm{~h}, 72 \mathrm{~h}$ and $96 \mathrm{~h}$. At each timepoint, the cells were collected and resuspended in FACS Buffer. CFSE intensity was measured on a LSRFortessa flow cytometer (BD Biosciences).

\section{Immunoprecipitation}

HeLa cells were seeded onto $150 \mathrm{~mm}$ tissue culture dishes at a density of $3.6 \times 10^{6}$ cells per dish $24 \mathrm{~h}$ prior to infection. The cells were infected with $C$. trachomatis $\mathrm{L} 2$ at a $\mathrm{MOI}$ of 5 or mock infected with HBSS by absorption for $2 \mathrm{~h}$ at $37^{\circ} \mathrm{C}$ rocking and then transitioned to $37^{\circ} \mathrm{C}$ and $5 \% \mathrm{CO}_{2}$ for $2 \mathrm{~h}$. Both cell populations were then transfected with $2 \mu \mathrm{g}$ of $3 \times \mathrm{xLAG}$-SNAP23 DNA supplemented with $7 \mu \mathrm{g}$ of empty pcDNA3.1+ plasmid at a $1 \mu \mathrm{g}$ of DNA:1 $\mu \mathrm{l}$ of Continuum transfection reagent (Gemini Bio-products) ratio and incubated for an additional $20 \mathrm{~h}$ at 
$37^{\circ} \mathrm{C}$ and $5 \% \mathrm{CO}_{2}$. At $24 \mathrm{~h}$ pi the cells were lysed in ice-cold lysis buffer (50 mM Tris, pH 8.0, $150 \mathrm{mM} \mathrm{NaCl}, 10 \mathrm{mM}$ EDTA, $5 \%$ glycerol, $1 \%$ Triton X-100) supplemented with $250 \mathrm{U} / \mathrm{ml}$ of Turbonuclease (Accelagen), $10 \mathrm{mM} \mathrm{NaF}, 5.4 \mathrm{mM} \mathrm{Na}_{3} \mathrm{VO}_{4}$, and protease inhibitor cocktail (APExBIO) for $1 \mathrm{~h}$ on ice. Samples were clarified by centrifugation at $20,000 \mathrm{xg}$ for $30 \mathrm{~min}$ at $4^{\circ} \mathrm{C}$ and then incubated with $50 \mu \mathrm{l}$ of settled Protein G Plus agarose (Calbiochem) for $30 \mathrm{~min}$ at $4^{\circ} \mathrm{C}$. Pre-cleared samples containing $6 \mathrm{mg}$ of total protein were then incubated with $30 \mu \mathrm{g}$ of mouse anti-FLAG antibody (Sigma, M2) overnight at $4^{\circ} \mathrm{C}$ rotating $(8 \mathrm{rpm})$. Antibody-antigen complexes were captured with $20 \mu \mathrm{l}$ of settled Protein G Plus agarose at $4^{\circ} \mathrm{C}$ for $2 \mathrm{~h}$, washed with lysis buffer, and eluted with SDS-PAGE sample buffer. Eluates and lysates $(40 \mu \mathrm{g})$ were analyzed by Western blot.

\section{Statistics}

A two-tailed student t-test was used to determine statistical differences between the means of two populations from at least three independent experiments. Statistical significance was assumed at $p$ values $<0.05$.

\section{ACKNOWLEDGMENTS}

The authors would like to acknowledge Drs. Michael Root, Christopher Snyder, Luis Sigal, Sangwon Kim (Thomas Jefferson University) and Margarida Correia-Neves (Life and Health Sciences Research Institute (ICVS), Portugal), as well as the members of the Paumet laboratory, for their critical discussions. We would also like to thank Drs. Ted Hackstadt (Rocky Mountain Laboratories, National Institutes of Health) for providing Chlamydia strains; Andrew Peden (University of Sheffield) for the HeLa C1 cell line; Paul

\section{REFERENCES}

1. WHO (2016). Global Health Sector Strategy on Sexually Transmitted Infections 2016-2021. World Health Organization Press, Geneva. Available at https://www.who.int/reproductivehealth/publications/ rtis/ghss-stis/en/. [Accessed 01.06.2019]

2. WHO (2018). Report on Global Sexually Transmitted Infection Surveillance. World Health Organization Press, Geneva. Available at https://www.who.int/reproductivehealth/publications/stissurveillance-2018/en/. [Accessed 01.06.2019]

3. Burton MJ, Mabey DC (2009). The global burden of trachoma: a review. PLoS Negl Trop Dis 3(10): e460. doi: 10.1371/journal.pntd.0000460

4. Mariotti SP, Pascolini D, Rose-Nussbaumer J (2009). Trachoma: global magnitude of a preventable cause of blindness. Br J Ophthalmol 93(5): 563-568. doi: 10.1136/bjo.2008.148494

5. Taylor HR, Burton MJ, Haddad D, West S, Wright H (2014). Trachoma. Lancet 384(9960): 2142-2152. doi: 10.1016/S01406736(13)62182-0

6. Ohman $H$, Tiitinen A, Halttunen M, Lehtinen M, Paavonen J, Surcel HM (2009). Cytokine polymorphisms and severity of tubal damage in women with Chlamydia-associated infertility. J Infect Dis 199(9): 1353-1359. doi: 10.1086/597620

7. Arnheim Dahlstrom L, Andersson K, Luostarinen T, Thoresen S, Ogmundsdottir H, Tryggvadottir L, Wiklund F, Skare GB, Eklund C, Sjolin K, Jellum E, Koskela P, Wadell G, Lehtinen M, Dillner J (2011). Prospective seroepidemiologic study of human papillomavirus and
Roche (NIH) for pCMV-Tag2b; and Sangwon Kim (Thomas Jefferson University) for the CRISPR-Cas9 vector used in this study. We would like to thank Maria Yolanda Covarrubias of the Bioimaging Shared Resource of the Sidney Kimmel Cancer Center (NCI 5 P30 CA-56036) for her assistance with image acquision. This work was supported by the National Institutes of Health grant R01Al116983 (F.P.) and by the Fundacao para a Ciencia e Tecnologia PhD fellowship $\mathrm{PD} / \mathrm{BD} / 113772 / 2015$, as part of the MD/PhD program of the University of Minho School of Medicine (T.M-B.).

\section{SUPPLEMENTAL MATERIAL}

All supplemental data for this article are available online at www.microbialcell.com.

\section{CONFLICT OF INTEREST}

The authors declare no conflicts of interest.

\section{COPYRIGHT}

(C) 2019 Monteiro-Brás et al. This is an open-access article released under the terms of the Creative Commons Attribution (CC BY) license, which allows the unrestricted use, distribution, and reproduction in any medium, provided the original author and source are acknowledged.

Please cite this article as: Tiago Monteiro-Brás, Jordan Wesolowski and Fabienne Paumet (2019). Depletion of SNAP-23 and Syntaxin 4 alters lipid droplet homeostasis during Chlamydia infection. Microbial Cell 7(2): 46-58. doi: 10.15698/mic2020.02.707

other risk factors in cervical cancer. Cancer Epidemiol Biomarkers Prev 20(12): 2541-2550. doi: 10.1158/1055-9965.EPI-11-0761

8. Dreses-Werringloer $U$, Padubrin I, Jurgens-Saathoff B, Hudson AP, Zeidler $\mathrm{H}$, Kohler L (2000). Persistence of Chlamydia trachomatis is induced by ciprofloxacin and ofloxacin in vitro. Antimicrob Agents Chemother 44(12): 3288-3297. doi: 10.1128/aac.44.12.32883297.2000

9. Zhu H, Shen Z, Luo H, Zhang W, Zhu X (2016). Chlamydia Trachomatis Infection-Associated Risk of Cervical Cancer: A Meta-Analysis. Medicine 95(13): e3077. doi: 10.1097/MD.0000000000003077

10. Abdelrahman YM, Belland RJ (2005). The chlamydial developmental cycle. FEMS Microbiol Rev 29(5): 949-959. doi 10.1016/j.femsre.2005.03.002

11. Moulder JW (1991). Interaction of chlamydiae and host cells in vitro. Microbiol Rev 55(1): 143-190. PMDI: 2030670

12. Jewett TJ, Fischer ER, Mead DJ, Hackstadt T (2006). Chlamydial TARP is a bacterial nucleator of actin. Proc Natl Acad Sci U S A 103(42): 15599-15604. doi: 10.1073/pnas.0603044103

13. Carabeo RA, Mead DJ, Hackstadt T (2003). Golgi-dependent transport of cholesterol to the Chlamydia trachomatis inclusion. Proc Natl Acad Sci U S A 100(11): 6771-6776. doi: 10.1073/pnas.1131289100

14. Hackstadt T, Scidmore MA, Rockey DD (1995). Lipid metabolism in Chlamydia trachomatisinfected cells: directed trafficking of Golgi- 
derived sphingolipids to the chlamydial inclusion. Proc Natl Acad Sci U S A 92(11): 4877-4881. doi: 10.1073/pnas.92.11.4877

15. Hackstadt T, Rockey DD, Heinzen RA, Scidmore MA (1996). Chlamydia trachomatis interrupts an exocytic pathway to acquire endogenously synthesized sphingomyelin in transit from the Golgi apparatus to the plasma membrane. EMBO J 15(5): 964-977. doi: 10.1002/j.1460-2075.1996.tb00433.x

16. Moore ER, Fischer ER, Mead DJ, Hackstadt T (2008). The chlamydial inclusion preferentially intercepts basolaterally directed sphingomyelin-containing exocytic vacuoles. Traffic 9(12): 2130- 2140. doi: 10.1111/j.1600-0854.2008.00828.x

17. Scidmore MA, Fischer ER, Hackstadt T (1996). Sphingolipids and glycoproteins are differentially trafficked to the Chlamydia trachomatis inclusion. J Cell Biol 134(2): 363-374. doi: 10.1083/jcb.134.2.363

18. Dumoux M, Clare DK, Saibil HR, Hayward RD (2012). Chlamydiae assemble a pathogen synapse to hijack the host endoplasmic reticulum. Traffic 13(12): 1612-1627. doi: 10.1111/tra.12002

19. Giles DK, Wyrick PB (2008). Trafficking of chlamydial antigens to the endoplasmic reticulum of infected epithelial cells. Microbes Infect 10(14-15): 1494-1503. doi: 10.1016/j.micinf.2008.09.001

20. Stanhope R, Flora E, Bayne C, Derre I (2017). IncV, a FFAT motifcontaining Chlamydia protein, tethers the endoplasmic reticulum to the pathogen-containing vacuole. Proc Natl Acad Sci U S A 114(45): 12039-12044. doi: 10.1073/pnas.1709060114

21. Boncompain G, Muller C, Meas-Yedid V, Schmitt-Kopplin P, Lazarow PB, Subtil A (2014). The intracellular bacteria Chlamydia hijack peroxisomes and utilize their enzymatic capacity to produce bacteriaspecific phospholipids. PLoS One 9(1): e86196. doi: 10.1371/journal.pone.0086196

22. Beatty WL (2006). Trafficking from CD63-positive late endocytic multivesicular bodies is essential for intracellular development of Chlamydia trachomatis. J Cell Sci 119(Pt 2): 350-359. doi: $10.1242 /$ jcs. 02733

23. Beatty WL (2008). Late endocytic multivesicular bodies intersect the chlamydial inclusion in the absence of CD63. Infect Immun 76(7): 2872-2881. doi: 10.1128/IAI.00129-08

24. Bastidas RJ, Elwell CA, Engel JN, Valdivia RH (2013). Chlamydial intracellular survival strategies. Cold Spring Harb Perspect Med 3(5): a010256. doi: 10.1101/cshperspect.a010256

25. Cocchiaro JL, Kumar Y, Fischer ER, Hackstadt T, Valdivia RH (2008). Cytoplasmic lipid droplets are translocated into the lumen of the Chlamydia trachomatis parasitophorous vacuole. Proc Natl Acad Sci U S A 105(27): 9379-9384. doi: 10.1073/pnas.0712241105

26. Saka HA, Thompson JW, Chen YS, Dubois LG, Haas JT, Moseley A, Valdivia RH (2015). Chlamydia trachomatis Infection Leads to Defined Alterations to the Lipid Droplet Proteome in Epithelial Cells. PLoS One 10(4): e0124630. doi: 10.1371/journal.pone.0124630

27. Cox JV, Abdelrahman YM, Peters J, Naher N, Belland RJ (2016). Chlamydia trachomatis utilizes the mammalian CLA1 lipid transporter to acquire host phosphatidylcholine essential for growth. Cell Microbiol 18(3): 305-318. doi: 10.1111/cmi.12523

28. Derre I, Swiss R, Agaisse H (2011). The lipid transfer protein CERT interacts with the Chlamydia inclusion protein IncD and participates to ER-Chlamydia inclusion membrane contact sites. PLoS Pathog 7(6): e1002092. doi: 10.1371/journal.ppat.1002092

29. Elwell CA, Jiang S, Kim JH, Lee A, Wittmann T, Hanada K, Melancon $P$, Engel JN (2011). Chlamydia trachomatis co-opts GBF1 and CERT to acquire host sphingomyelin for distinct roles during intracellular development. PLoS Pathog 7(9): e1002198. doi: 10.1371/journal.ppat.1002198
30. Hackstadt T (2000). Redirection of host vesicle trafficking pathways by intracellular parasites. Traffic 1(2): 93-99. doi.

31. Triboulet S, Subtil A (2019). Make It a Sweet Home: Responses of Chlamydia trachomatis to the Challenges of an Intravacuolar Lifestyle. Microbiol Spectr 7(2). doi: 10.1128/microbiolspec.BAI-0005-2019

32. McNew JA, Parlati F, Fukuda R, Johnston RJ, Paz K, Paumet F, Sollner TH, Rothman JE (2000). Compartmental specificity of cellular membrane fusion encoded in SNARE proteins. Nature 407(6801): 153159. doi: $10.1038 / 35025000$

33. Paumet F, Rahimian V, Rothman JE (2004). The specificity of SNARE-dependent fusion is encoded in the SNARE motif. Proc Natl Acad Sci U S A 101(10): 3376-3380. doi: 10.1073/pnas.0400271101

34. Sollner T, Bennett MK, Whiteheart SW, Scheller RH, Rothman JE (1993). A protein assemblydisassembly pathway in vitro that may correspond to sequential steps of synaptic vesicle docking, activation, and fusion. Cell 75(3): 409-418. doi: 10.1016/0092-8674(93)90376-2

35. Sollner T, Whiteheart SW, Brunner M, Erdjument-Bromage $H$, Geromanos S, Tempst P, Rothman JE (1993). SNAP receptors implicated in vesicle targeting and fusion. Nature 362(6418): 318-324. doi $10.1038 / 362318 \mathrm{a} 0$

36. Lucas AL, Ouellette SP, Kabeiseman EJ, Cichos KH, Rucks EA (2015). The trans-Golgi SNARE syntaxin 10 is required for optimal development of Chlamydia trachomatis. Front Cell Infect Microbiol 5: 68. doi: 10.3389/fcimb. 2015.00068

37. Kabeiseman EJ, Cichos K, Hackstadt T, Lucas A, Moore ER (2013). Vesicle-associated membrane protein 4 and syntaxin 6 interactions at the chlamydial inclusion. Infect Immun 81(9): 3326-3337. doi: 10.1128/IAI.00584-13

38. Moore ER, Mead DJ, Dooley CA, Sager J, Hackstadt T (2011). The trans-Golgi SNARE syntaxin 6 is recruited to the chlamydial inclusion membrane. Microbiology 157(Pt 3 ): 830-838. doi: 10.1099/mic.0.045856-0

39. Wong PP, Daneman N, Volchuk A, Lassam N, Wilson MC, Klip A, Trimble WS (1997). Tissue distribution of SNAP-23 and its subcellular localization in 3T3-L1 cells. Biochem Biophys Res Commun 230(1): 6468. doi: 10.1006/bbrc.1996.5884

40. Bennett MK, Garcia-Arraras JE, Elferink LA, Peterson K, Fleming AM, Hazuka CD, Scheller RH (1993). The syntaxin family of vesicular transport receptors. Cell 74(5): 863-873. doi: 10.1016/0092 8674(93)90466-4

41. Kabeiseman EJ, Cichos KH, Moore ER (2014). The eukaryotic signal sequence, YGRL, targets the chlamydial inclusion. Front Cell Infect Microbiol 4: 129. doi: 10.3389/fcimb.2014.00129

42. Ravichandran V, Chawla A, Roche PA (1996). Identification of a novel syntaxin- and synaptobrevin/VAMP-binding protein, SNAP-23, expressed in non-neuronal tissues. J Biol Chem 271(23): 13300-13303. doi: $10.1074 / j b c .271 .23 .13300$

43. Gordon DE, Bond LM, Sahlender DA, Peden AA (2010). A targeted siRNA screen to identify SNAREs required for constitutive secretion in mammalian cells. Traffic 11(9): 1191-1204. doi: 10.1111/j.1600 0854.2010.01087.x

44. Scidmore MA, Rockey DD, Fischer ER, Heinzen RA, Hackstadt T (1996). Vesicular interactions of the Chlamydia trachomatis inclusion are determined by chlamydial early protein synthesis rather than route of entry. Infect Immun 64(12): 5366-5372. PMID: 8945589

45. Bostrom P, Andersson L, Rutberg M, Perman J, Lidberg U, Johansson BR, Fernandez- Rodriguez J, Ericson J, Nilsson T, Boren J, Olofsson SO (2007). SNARE proteins mediate fusion between cytosolic lipid droplets and are implicated in insulin sensitivity. Nat Cell Biol 9(11): 1286-1293. doi: 10.1038/ncb1648 
46. Sollner TH (2007). Lipid droplets highjack SNAREs. Nat Cell Biol 9(11): 1219-1220. doi: 10.1038/ncb1107-1219

47. Kumar Y, Cocchiaro J, Valdivia RH (2006). The obligate intracellular pathogen Chlamydia trachomatis targets host lipid droplets. Curr Biol 16(16): 1646-1651. doi: 10.1016/j.cub.2006.06.060

48. Sharma M, Recuero-Checa MA, Fan FY, Dean D (2018). Chlamydia trachomatis regulates growth and development in response to host cell fatty acid availability in the absence of lipid droplets. Cell Microbiol 20(2). doi: 10.1111/cmi.12801

49. Gao Q, Goodman JM (2015). The lipid droplet-a well-connected organelle. Front Cell Dev Biol 3: 49. doi: 10.3389/fcell.2015.00049

50. Tauchi-Sato K, Ozeki S, Houjou T, Taguchi R, Fujimoto T (2002). The surface of lipid droplets is a phospholipid monolayer with a unique Fatty Acid composition. J Biol Chem 277(46): 44507- 44512. doi: 10.1074/jbc.M207712200

51. Olzmann JA, Carvalho $P$ (2019). Dynamics and functions of lipid droplets. Nat Rev Mol Cell Biol 20(3): 137-155. doi: 10.1038/s41580018-0085-z

52. Wilfling F, Wang $H$, Haas JT, Krahmer N, Gould TJ, Uchida A, Cheng JX, Graham M, Christiano R, Frohlich F, Liu X, Buhman KK, Coleman RA, Bewersdorf J, Farese RV, Jr., Walther TC (2013). Triacylglycerol synthesis enzymes mediate lipid droplet growth by relocalizing from the ER to lipid droplets. Dev Cell 24(4): 384-399. doi: 10.1016/j.devcel.2013.01.013
53. Bostrom P, Rutberg M, Ericsson J, Holmdahl P, Andersson L, Frohman MA, Boren J, Olofsson SO (2005). Cytosolic lipid droplets increase in size by microtubule-dependent complex formation. Arterioscler Thromb Vasc Biol 25(9): 1945-1951. doi 10.1161/01.ATV.0000179676.41064.d4

54. Bauler LD, Hackstadt T (2014). Expression and targeting of secreted proteins from Chlamydia trachomatis. J Bacteriol 196(7): 13251334. doi: 10.1128/JB.01290-13

55. Tellam JT, Macaulay SL, McIntosh S, Hewish DR, Ward CW, James DE (1997). Characterization of Munc-18c and syntaxin-4 in 3T3-L1 adipocytes. Putative role in insulindependent movement of GLUT-4. J Biol Chem 272(10): 6179-6186. doi: 10.1074/jbc.272.10.6179

56. Antonin W, Holroyd C, Fasshauer D, Pabst S, Von Mollard GF, Jahn $R$ (2000). A SNARE complex mediating fusion of late endosomes defines conserved properties of SNARE structure and function. EMBO J 19(23): 6453-6464. doi: 10.1093/emboj/19.23.6453

57. Haeussler M, Schonig K, Eckert H, Eschstruth A, Mianne J, Renaud JB, Schneider-Maunoury S, Shkumatava A, Teboul L, Kent J, Joly JS, Concordet JP (2016). Evaluation of off-target and on-target scoring algorithms and integration into the guide RNA selection tool CRISPOR. Genome Biol 17(1): 148. doi: 10.1186/s13059-016-1012-2

58. Doench JG, Fusi N, Sullender M, Hegde M, Vaimberg EW, Donovan KF, Smith I, Tothova Z, Wilen C, Orchard R, Virgin HW, Listgarten J, Root DE (2016). Optimized sgRNA design to maximize activity and minimize off-target effects of CRISPR-Cas9. Nat Biotechnol 34(2): 184191. doi: $10.1038 / \mathrm{nbt} .3437$ 